\title{
Correction to: Bioformulated Hesperidin-Loaded PLGA Nanoparticles Counteract the Mitochondrial-Mediated Intrinsic Apoptotic Pathway in Cancer Cells
}

\author{
Krithiga Balakrishnan ${ }^{1,2}$. Sangeetha C. Casimeer ${ }^{3}$. Alaa Yousef Ghidan ${ }^{4}$ - Fatima Yousef Ghethan ${ }^{5}$. \\ Karthikkumar Venkatachalam ${ }^{6} \cdot$ Anbu Singaravelu $^{1}$
}

Published online: 31 October 2020

(c) Springer Science+Business Media, LLC, part of Springer Nature 2020

\section{Correction to: \\ Journal of Inorganic and Organometallic Polymers and Materials \\ https://doi.org/10.1007/s10904-020-01746-9}

We have noticed an inadvertent error in our article "Bioformulated Hesperidin-Loaded PLGA Nanoparticles Counteract the Mitochondrial-Mediated Intrinsic Apoptotic Pathway in Cancer Cells" [1].
The published Fig. 9 is apoptotic features of Hesperidin, Hes-PLGA-NPs, and doxorubicin-treated HEp-2 cells using annexin V/PI using flow cytometer. The panels for control and doxorubicin figures both are the same picture. We have attached a corrected version of Fig. 9. This error does not change the scientific conclusions of the article in any way. The authors apologize for this error.

The original article can be found online at https://doi.org/10.1007/ s10904-020-01746-9.

Anbu Singaravelu

scanbu@gmail.com

1 Department of Biochemistry, Sacred Heart College

(Autonomous), Tirupattur, Tamil Nadu 635601, India

2 Department of Biochemistry, Thiruvalluvar Arts and Science College, Kurinjipadi, Cuddalore, Tamil Nadu 607302, India

3 Department of Physics, Sri Padmavati Mahila Visvavidyalayam (Women's University), Tirupati, Andhra Pradesh 517502, India

4 Department of Pharmacy, Aqaba University of Technology, Aqaba, Jordan

5 Pharmaceutical Service Administration, Quality and Medication Safety Unit, King Abdullah Medical City, Makkah, Saudi Arabia

6 Department of Pharmacology and Therapeutics, College of Medicine and Health Sciences, UAE University, Al Ain, United Arab Emirates 
Fig. 9 Apoptotic features of Hesperidin, Hes-PLGA-NPs, and doxorubicin-treated HEp-2 cells using annexin V/PI using flow cytometer
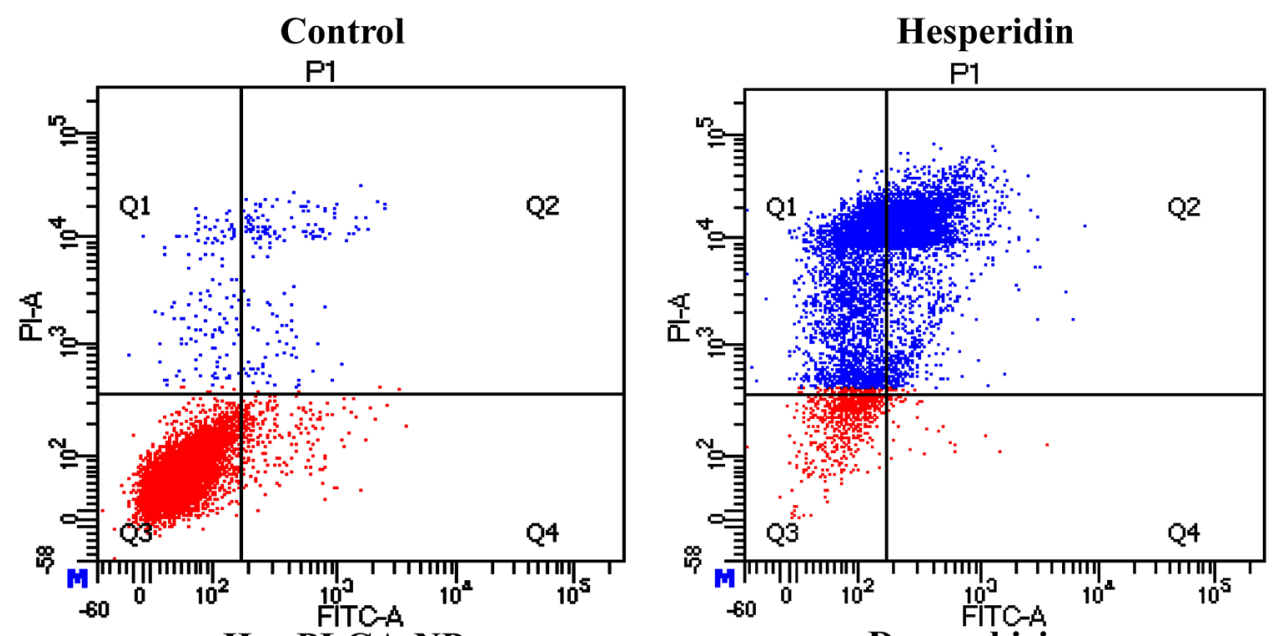

Hes-PLGA-NPs

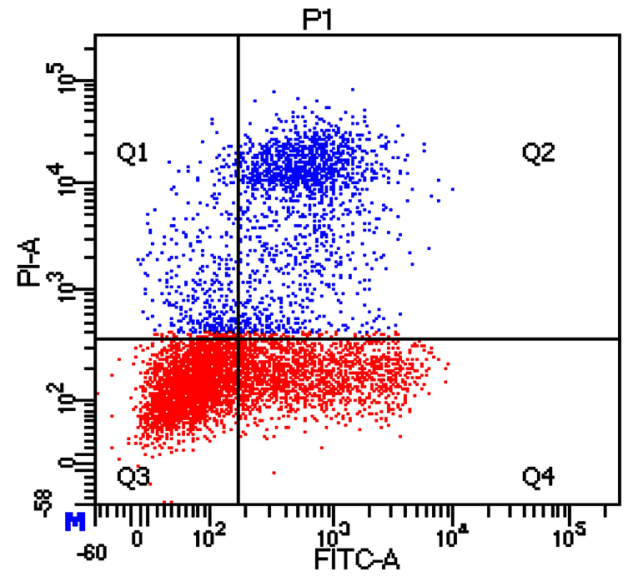

Doxorubicin

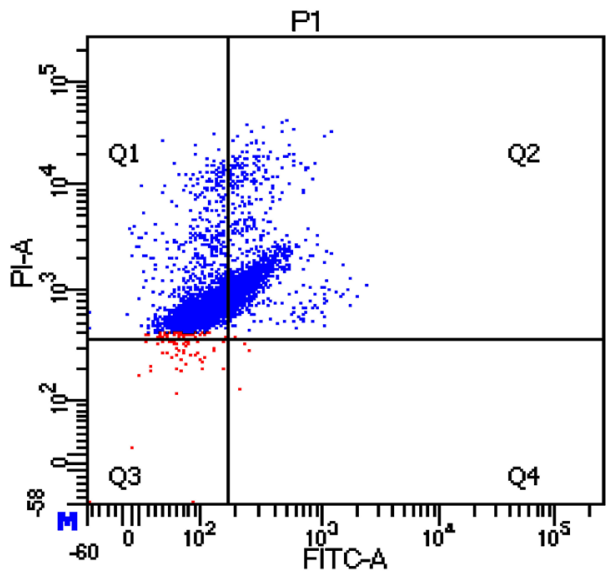

\section{Reference}

1. K. Balakrishnan, S.C. Casimeer, A.Y. Ghidan, F.Y. Ghethan, K. Venkatachalam, A. Singaravelu, Bioformulated hesperidin-loaded PLGA nanoparticles counteract the mitochondrial-mediated intrinsic apoptotic pathway in cancer cells. J. Inorg. Organomet. Polym. (2020). https://doi.org/10.1007/s10904-020-01746-9
Publisher's Note Springer Nature remains neutral with regard to jurisdictional claims in published maps and institutional affiliations. 